\title{
STAVOVI UČENIKA PREMA NASTAVI GLAZBENE KULTURE I GLAZBENE UMJETNOSTI
}

\author{
Izv. prof. dr. sc. Snježana Dobrota \\ Filozofski fakultet Sveučilišta u Splitu \\ Odsjek za učiteljski studij \\ Ružica Conar, magistrica primarnog obrazovanja \\ Split, Hrvatska
}

\section{Sažetak:}

U radu su istraženi stavovi učenika osnovnih škola i gimnazija prema nastavi Glazbene kulture i Glazbene umjetnosti s obzirom na spol, dob, obiteljsko okruženje, dodatnu glazbenu poduku, preferiranje klasične glazbe te preferencije određenih aktivnosti nastave glazbe. Tijekom istraživanja primijenjen je upitnik općih podataka te upitnik za ispitivanje stavova učenika prema predmetu Glazbena kultura / Glazbena umjetnost. Istraživanje je provedeno na uzorku od 245 učenika trećeg, četvrtog, sedmog i osmog razreda osnovne škole te trećeg i četvrtog razreda gimnazije.

Rezultatima ovoga istraživanja potvrđeno je kako gimnazijalci u odnosu na učenike osnovne škole, provode više vremena dnevno slušajući glazbu. Učenici koji preferiraju klasičnu glazbu i učenici čiji roditelji slušaju klasičnu glazbu imaju pozitivnije stavove prema Glazbenoj kulturi / Glazbenoj umjetnosti. Rezultatima istraživanja potvrđeno je da mlađi učenici u odnosu na starije, imaju pozitivnije stavove prema nastavi glazbe. Slušanje je aktivnost nastave glazbe koju učenici najviše preferiraju, dok najmanje pozitivne stavove imaju prema glazbenom stvaralaštvu. Nije potvrđena povezanost dodatne glazbene poduke i spola na stavove prema nastavi glazbe.

Ključne riječi: glazbene preferencije, nastava glazbe, osnovna škola, srednja škola, stavovi.

\section{Uvod}

Cilj je nastave glazbe u osnovnoj školi „uvođenje učenika u glazbenu kulturu, upoznavanje osnovnih elemenata glazbenog jezika, razvijanje glazbene kreativnosti, uspostavljanje i usvajanje mjerila za (kritičko i estetsko) procjenjivanje glazbe“ (Nastavni plan i program, 2006, str. 66). Program nastave glazbe je otvoren, što znači da je učitelj slobodan u izboru načina aktivnog muziciranja, dok slušanje i upoznavanje glazbe predstavlja njegov obvezni dio.

U nižim razredima osnovne škole nastava glazbe obuhvaća aktivnosti pjevanja, slušanja, sviranja i glazbene kreativnosti. Učenici pjevaju autorske i tradicijske pjesme, sviraju ritam i dobe brojalica i pjesama, slušaju autorske i tradicijske skladbe i u njima uočavaju različite glazbeno-izražajne sastavnice te stvaraju različite melodijske, ritamske i meloritamske cjeline (Nastavni plan i program, 2006).

Od četvrtog do šestog razreda osnovne škole nastava glazbe obuhvaća pjevanje, slušanje, slušanje, poznavanje glazbe, izvođenje glazbe, glazbeno pismo, učeničko improvizirano ritmiziranje te kretanje na glazbu (Nastavni plan i program, 2006). Aktivnosti nastave glazbe u sedmom i osmom razredu osnovne škole reducirane su na pjevanje, slušanje i upoznavanje glazbe te sviranje i stvaralaštvo (Nastavni plan i program, 2006). 
Nastava glazbe u srednjim školama ostvaruje se prema Nastavnom planu i programu za gimnazije (Nastavni plan i program za gimnazije. Glazbena umjetnost, 1999), a njezin je cilj sveobuhvatan odgoj mladih u kulturi, upoznavanje temeljnih značajki glazbe te aktivno sudioništvo u glazbenom životu (koncerti, kazališne priredbe, slušanje umjetničke glazbe, itd.). Nastava glazbe koncipirana je prema dijakronijskom modelu, u kojemu "program uglavnom slijedi kronološki tijek razvoja glazbe i njenih stilova" (Nastavni plan i program za gimnazije. Glazbena umjetnost, 1999, 77) pa se tako u prvom razredu obrađuju sastavnice glazbenoga govora te razvoj glazbe od njenih početaka do renesanse, u drugom se razredu obrađuje barok, galantni stil i bečka klasika (17. i 18. stoljeće), treći razred obuhvaća razdoblja romantizma i impresionizma, dok je četvrti razred posvećen razvojnim pravcima glazbene umjetnosti 20. stoljeća (Nastavni plan i program za gimnazije. Glazbena umjetnost, 1999). U dvogodišnjem programu glazbene umjetnosti za prvi razred predviđena je obrada Uvoda u glazbenu umjetnost i Razvoja glazbe od njenih početaka do kraja 18. stoljeća, dok se u drugom razredu obrađuje Pregled razvoja glazbene umjetnosti od Beethovena do naših dana (19. i 20. stoljeće) (Nastavni plan i program za gimnazije. Glazbena umjetnost, 1999).

Stav predstavlja ukupnu evaluaciju nekog objekta (Bohner, 2003), odnosno „psihološku tendenciju koja se izražava vrednovanjem nekog objekta uz određeni stupanj sklonosti ili nesklonosti“ (Eagly i Chaiken, 1993, str. 23). Stavovi za pojedinca imaju spoznajnu funkciju koja se očituje u tome da oni upravljaju, organiziraju i pojednostavljuju obradu informacija. Utilitarna funkcija stava odnosi se na to da pozitivan ili negativan stav upućuje na to možemo li od određenog objekta očekivati nagradu ili kaznu, slijedom čega možemo usmjeriti svoje ponašanje. Stavovi imaju i funkciju socijalnog identiteta, što znači da omogućuju izražavanje vrijednosti pojedinca i identifikaciju s određenim skupinama. Funkcija održavanja samopoštovanja odražava se u tome da stavovi omogućuju pojedincu da se odvoji od negativnih i poveže s pozitivnim objektima (Bohner, 2003).

Problematika stavova tijesno je povezana s odgojem i obrazovanjem pa tako postoji velik broj istraživanja koja se bave ispitivanjem stavova učenika prema školi i prema različitim nastavnim predmetima (Haladyna i Thomas, 2015; Holfve-Sabel, 2006; Labak, Heffer, i Radanović, 2014). Rezultati istraživanja stavova učenika prema nastavi glazbe (Dobrota i Reić Ercegovac, 2011; Dobrota i Obradović, 2012; Sunara, 2016; Barbarić, 2017) uglavnom potvrđuju kako učenici imaju pozitivne stavove, iako s porastom dobi opada interes prema tom predmetu. I Harland (2000) upozorava na opadanje popularnosti nastave glazbe u srednjim školama, što objašnjava postojanjem kulturne disonance između sadržaja nastave glazbe u srednjoj školi i glazbe koju tinejdžeri slušaju izvan škole. Na slične trendove ukazuje i Ross $(1995 ; 1998)$, ističući kako sadržaj predmeta nije prilagođen izazovima i promjenama modernog društva u kojemu učenici žive.

\section{CII, PROBLEM I HIPOTEZE ISTRAŽIVANJA}

Cilj je istraživanja ispitati stavove učenika prema nastavi Glazbene kulture / Glazbene umjetnosti s obzirom na dob, spol, obiteljsko okruženje i dodatnu glazbenu poduku te utjecaj spola i dobi na preferiranje različitih aktivnosti nastave glazbe. U skladu s formuliranim ciljem postavljeni su sljedeći problemi istraživanja:

1. Ispitati kakva je uloga glazbe u slobodnom vremenu učenika;

2. Ispitati postoji li utjecaj obiteljskog okruženja i dodatne glazbene poduke na stavove učenika prema Glazbenoj kulturi / Glazbenoj umjetnosti;

3. Ispitati postoji li utjecaj dobi i spola na stavove učenika prema Glazbenoj kulturi / Glazbenoj umjetnosti; 
4. Ispitati postoji li utjecaj dobi i spola na učeničke preferencije različitih aktivnosti nastave glazbe.

Na temelju definiranog cilja i problema istraživanja postavljene su sljedeće hipoteze:

H1: Dnevno slušanje glazbe ne razlikuje se s obzirom na dob učenika.

H2: Učenici čiji roditelji slušaju klasičnu glazbu imaju pozitivnije stavove prema Glazbenoj kulturi / Glazbenoj umjetnosti.

H3: Učenici koji su pohađali ili pohađaju dodatnu glazbenu poduku imaju pozitivnije stavove prema Glazbenoj kulturi / Glazbenoj umjetnosti.

H4: Učenici koji preferiraju klasičnu glazbu imaju pozitivnije stavove prema Glazbenoj kulturi / Glazbenoj umjetnosti.

H5: Mlađi učenici u odnosu na starije učenike imaju pozitivnije stavove prema Glazbenoj kulturi / Glazbenoj umjetnosti.

H6: Učenice u odnosu na učenike imaju pozitivnije stavove prema Glazbenoj kulturi / Glazbenoj umjetnosti.

H7: Postoji utjecaj dobi na preferiranje aktivnosti nastave glazbe.

H8: Postoji utjecaj spola na preferiranje aktivnosti nastave glazbe.

\section{Metoda}

\section{Sudionici}

Ispitivanje je provedeno u Splitu (OŠ Marjan, OŠ Blatine-Škrape, OŠ Spinut, OŠ Lučac), Trogiru (OŠ Majstora Radovana) i Kaštel Štafiliću (srednja škola Braća Radić, smjer opća

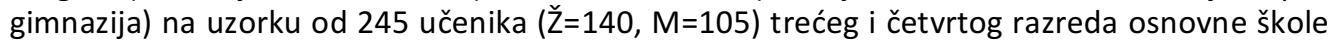
$(\mathrm{N}=83)$, sedmog i osmog razreda osnovne škole $(\mathrm{N}=82)$ te trećeg i četvrtog razreda opće gimnazije $(\mathrm{N}=80)$ (tablica 1$)$.

Tablica 1. Struktura uzorka $(\mathrm{N}=225)$

\begin{tabular}{|c|c|c|c|}
\hline SPOL & $\mathbf{N}$ & RAZRED & $\mathbf{N}$ \\
\hline \multirow[t]{2}{*}{$M$} & \multirow[t]{2}{*}{105} & 3 & \multirow[t]{2}{*}{83} \\
\hline & & 4 & \\
\hline \multirow[t]{4}{*}{$\bar{Z}$} & \multirow[t]{4}{*}{140} & 7 & \multirow[t]{2}{*}{82} \\
\hline & & 8 & \\
\hline & & $3_{\text {gimn. }}$ & \multirow[t]{2}{*}{80} \\
\hline & & $4_{\text {gimn }}$. & \\
\hline Ukupno & \multicolumn{3}{|l|}{245} \\
\hline
\end{tabular}

\section{Instrument i postupak ispitivanja}

Za potrebe istraživanja konstruiran je upitnik (Prilog 1) koji sadrži dva dijela. U prvom dijelu nalaze se pitanja koja se odnose na sociodemografska obilježja učenika (spol i dob), prosječno dnevno slušanje glazbe, obiteljsko okruženje, pohađanje dodatne glazbene poduke i preferencije klasične glazbe. Drugi dio upitnika sadrži pitanja kojima se ispituju stavovi učenika prema predmetu Glazbena kultura (važnost predmeta, procjena koliko predmet opterećuje ili opušta, težina predmeta, korisnost predmeta te rangiranje predmeta u odnosu na ostale pred- 
mete iz Nastavnog plana i programa) te pitanje kojim se ispituje prema kojoj aktivnosti nastave glazbe učenici pokazuju najveću sklonost.

Sudionicima je objašnjena svrha provođenja istraživanja, zajamčena im je anonimnost, te su zamoljeni da iskreno i precizno odgovaraju na pitanja.

\section{Rezultati i diskusija}

\section{H1: Dnevno slušanje glazbe ne razlikuje se s obzirom na dob učenika.}

Kako bismo testirali prvu hipotezu, proveden je Kruskal-Wallis test čiji rezultati upućuju na to da gimnazijalci značajno više slušaju glazbu u odnosu na učenike trećih i četvrtih, odnosno sedmih i osmih razreda osnovne škole, između kojih nema značajne razlike u dnevnom slušanju glazbe (tablica 2, slika 1). Time je odbačena prva hipoteza.

Dobiveni rezultati u skladu su s rezultatima brojnih istraživanja koja potvrđuju kako glazba ima važnu ulogu u životu mladih (Barbarić, 2017; Brown i Bobkowski, 2011; McPherson, 2006; Miranda, 2013; North, Hargreaves, i O'Neill, 2000). Slušanje glazbe za slušatelja ima brojne funkcije, od formiranja identiteta do prenošenja osobnih vrijednosti, stavova i percepcije svijeta i ljudi u njemu (Arnett, 1995; Larson, 1995; North i Hargreaves, 1999). Rentrfow i Gosling $(2003 ; 2006)$ smatraju da je slušanje glazbe najvažnija aktivnost slobodnog vremena većine ljudi te da uvidom u glazbene preferencije upoznajemo i njihovu osobnost.

Tablica 2. Razlike u dnevnom slušanju glazbe s obzirom na dob

\begin{tabular}{|c|c|c|c|}
\hline Dobna skupina & C & $H(2, \mathrm{~N}=245)$ & $\mathbf{p}$ \\
\hline 1 (3-4 r.oš) & 2 & \multirow[t]{3}{*}{27,96} & \multirow[t]{3}{*}{0,00} \\
\hline 2 (7-8 r.oš) & 2 & & \\
\hline 3 (3-4 r.gimnazije) & 3 & & \\
\hline
\end{tabular}

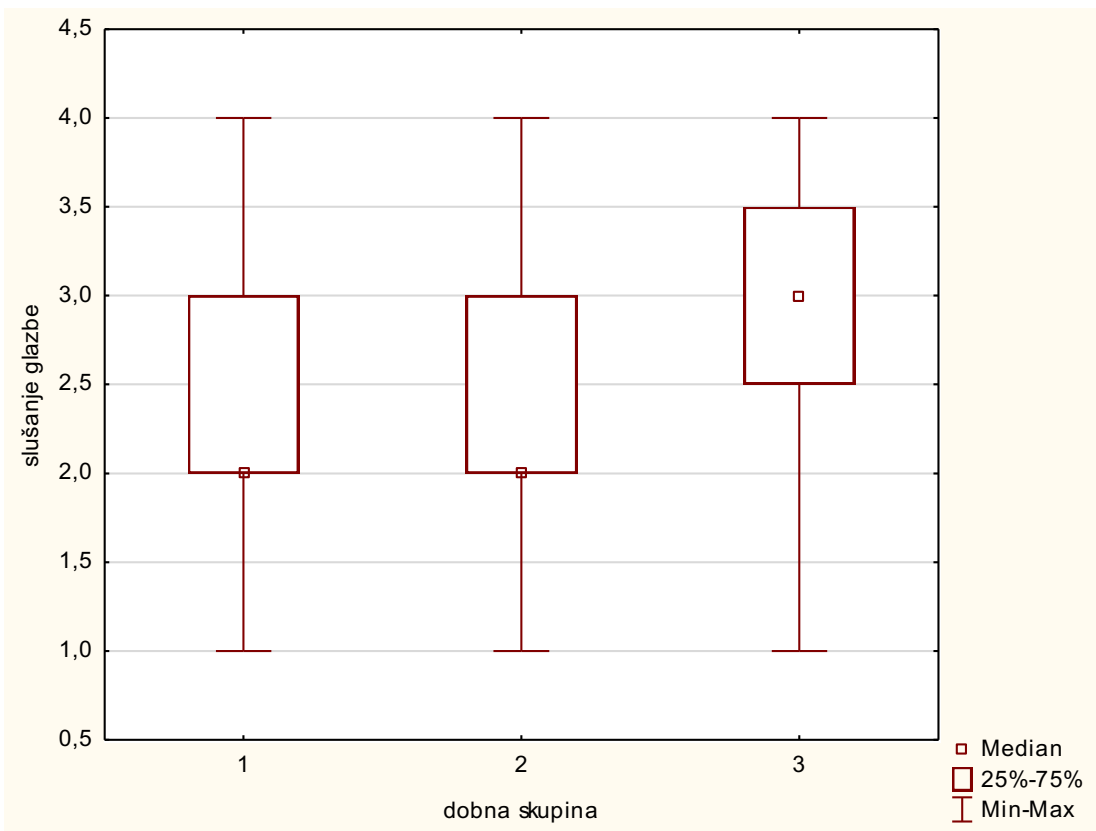

Slika 1. Razlike u dnevnom slušanju glazbe s obzirom na dob 


\section{H2: Učenici čiji roditelji slušaju klasičnu glazbu imaju pozitivnije stavove prema Glazbenoj kulturi / Glazbenoj umjetnosti.}

Kako bi se provjerila druga hipoteza, proveden je Mann-Whitney U-test pri čemu su stavovi kao zavisna varijabla, uključivali četiri komponente i to procjenu važnosti predmeta, opterećenosti predmetom, težinu predmeta i njegovu korisnost. Rezultati potvrđuju kako se stavovi prema predmetu Glazbena kultura / Glazbena umjetnost značajno razlikuju s obzirom na to slušaju li roditelji učenika klasičnu glazbu ili ne (tablica 3). Učenici čiji roditelji slušaju klasičnu glazbu imaju značajno pozitivnije stavove prema nastavi glazbe u odnosu na učenike čiji roditelji ne slušaju klasičnu glazbu, čime je potvrđena postavljena hipoteza.

Tablica 3. Razlike u stavovima prema Glazbenoj kulturi / Glazbenoj umjetnosti s obzirom na obiteljsko okruženje

\begin{tabular}{|l|c|c|c|c|}
\hline Obiteljsko okruženje & C & U & Z & p \\
\cline { 1 - 3 } roditelji ne slušaju klasičnu glazbu & 7 & 3094,0 & $-3,84$ & 0,00 \\
\cline { 1 - 2 } roditelji slušaju klasičnu glazbu & 8 & & & \\
\hline
\end{tabular}

H3: Učenici koji su pohađali ili pohađaju dodatnu glazbenu poduku imaju pozitivnije stavove prema Glazbenoj kulturi / Glazbenoj umjetnosti.

Kako bi se testirala navedena hipoteza, ponovno je proveden Mann-Whitney $U$ test čiji rezultati pokazuju kako dodatna glazbena poduka ne utječe na stavove učenika prema predmetima Glazbena kultura / Glazbena umjetnost (tablica 4), čime je odbačena postavljena hipoteza.

Tablica 4. Razlike u stavovima prema Glazbenoj kulturi / Glazbenoj umjetnosti s obzirom na pohađanje dodatne glazbene poduke

\begin{tabular}{|l|c|c|c|c|}
\hline Dodatna glazbena poduka & C & U & z & p \\
\cline { 1 - 3 } da & 8 & 3784,50 & $-0,96$ & 0,34 \\
\cline { 1 - 2 } & 7,5 & & & \\
\hline
\end{tabular}

H4: Učenici koji preferiraju klasičnu glazbu imaju pozitivnije stavove prema Glazbenoj kulturi / Glazbenoj umjetnosti.

Kako bi se ispitalo utječe li preferiranje klasične glazbe na stavove prema Glazbenoj kulturi / Glazbenoj umjetnosti, proveden je Kruskal-Wallis test. Rezultati potvrđuju kako se stavovi učenika prema predmetima Glazbena kultura / Glazbena umjetnost značajno razlikuju s obzirom na to preferiraju li klasičnu glazbu ili ne (tablica 5). Tako učenici kojima se najmanje sviđa klasična glazba, imaju i najmanje pozitivne stavove prema nastavi glazbe, dok najpozitivnije stavove prema nastavi glazbe imaju oni kojima se klasična glazba najviše sviđa. Time je potvrđena četvrta hipoteza. Dobiveni rezultati u skladu su s rezultatima Dobrote (2016) u čijem je istraživanju potvrđen pozitivan utjecaj izloženosti klasičnoj glazbi na stavove prema klasičnoj glazbi i nastavi glazbe.

Tablica 5. Razlike u stavovima prema Glazbenoj kulturi / Glazbenoj umjetnosti s obzirom na preferencije klasične glazbe

\begin{tabular}{|l|l|c|c|}
\hline Preferencije klasične glazbe & C & H (2, N=245) & p \\
\cline { 1 - 2 } uopće mi se ne sviđa & 6 & \multirow{2}{*}{0,00} \\
\cline { 1 - 2 } sviđa mi se samo neka klasična glazba & 7 & \\
\cline { 1 - 2 } sviđa mi se & 8 & & \\
\hline
\end{tabular}


H5: Mlađi učenici u odnosu na starije učenike imaju pozitivnije stavove prema Glazbenoj kulturi / Glazbenoj umjetnosti.

Kako bi se testirale razlike između učenika razredne nastave $(\mathrm{N}=83)$, predmetne nastave $(\mathrm{N}=82)$ i gimnazijalaca $(80)$ u stavovima prema predmetima Glazbena kultura / Glazbena umjetnost, proveden je Kruskal-Wallis test. Rezultati upućuju na to da među sudionicima različite dobi postoje značajne razlike u stavovima prema Glazbenoj kulturi / Glazbenoj umjetnosti, pri čemu učenici razredne nastave imaju najpozitivniji stav prema predmetu (tablica 6). Time je potvrđena postavljena hipoteza.

Dobiveni rezultati u skladbu su s rezultatima brojnih istraživanja (Barbarić, 2017; Dobrota i Obradović, 2012; Haladyna i Thomas, 2015) koji potvrđuju kako mlađi učenici u odnosu na starije imaju pozitivnije stavove prema nastavi glazbe.

Tablica 6. Utjecaj dobi na stavove prema predmetu Glazbena kultura / Glazbena umjetnost

\begin{tabular}{|l|c|c|c|}
\hline Dobna skupina & C & H (2,N=245) & p \\
\hline 1 (3-4 r.oš) & 8 & \multirow{2}{*}{34,25} & 0,00 \\
\cline { 1 - 2 } 2 (7-8 r.oš) & 7 & & \\
\cline { 1 - 2 } 3 (3-4 r.gimnazije) & 7 & & \\
\hline
\end{tabular}

H6: Učenice u odnosu na učenike imaju pozitivnije stavove prema Glazbenoj kulturi / Glazbenoj umjetnosti.

Kako bi se testirala navedena hipoteza proveden je Mann-Whitney $U$ test, čiji rezultati pokazuju kako spol ne utječe na stavove učenika prema predmetima Glazbena kultura / Glazbena umjetnost (tablica 7). Time je odbačena postavljena hipoteza.

Dobiveni rezultati nisu u skladbu s rezultatima brojnih istraživanja koja ukazuju na to da djevojke imaju uglavnom pozitivnije stavove prema glazbi u odnosu na dječake. Tako su Crowther i Durkin (1982) proveli istraživanje na sudionicima u dobi od dvanaest do osamnaest godina i uočili da je to posebno evidentno u mlađim dobnim skupinama te da učenice u odnosu na učenike češće sudjeluju u glazbenim aktivnostima.

Tablica 7. Utjecaj spola na stavove prema predmetu Glazbena kultura / Glazbena umjetnost

\begin{tabular}{|l|c|c|c|c|}
\hline Spol & C & U & z & p \\
\cline { 1 - 2 } muško & 6,98 & 6716,00 & 1,15 & 0,25 \\
\cline { 1 - 2 } žensko & 7,97 & & & \\
\hline
\end{tabular}

\section{H7: Postoji utjecaj dobi na preferiranje aktivnosti nastave glazbe.}

Kako bi se istražilo postojanje utjecaja dobi na preferiranje pojedinih aktivnosti nastave glazbe, proveden je hi-kvadrat test s varijablama dobi i aktivnostima nastave glazbe. Nije uočena značajna razlika između učenika razredne i predmetne nastave $\left(\chi^{2}=0,01 ; d f=2 ; p=0,99\right)$. Naime, učenici obiju skupina najviše preferiraju slušanje glazbe, slijedi pjevanje i nakon njega sviranje, dok niti jedan učenik nije odabrao glazbeno stvaralaštvo (slika 2). Time je odbačena postavljena hipoteza.

Razmatrajući stavove učenika prema različitim aktivnostima nastave glazbe, Rojko ističe kako mladi generalno vole pjevati, ali ne one pjesme koje pjevaju u školi (Rojko, 2012, str. 61). S druge strane Klausmeier te Eckhardt i Lück (prema Rojko, 2012, str. 61) smatraju da se s porastom dobi pjeva sve manje te da opada entuzijazam za pjevanje. 


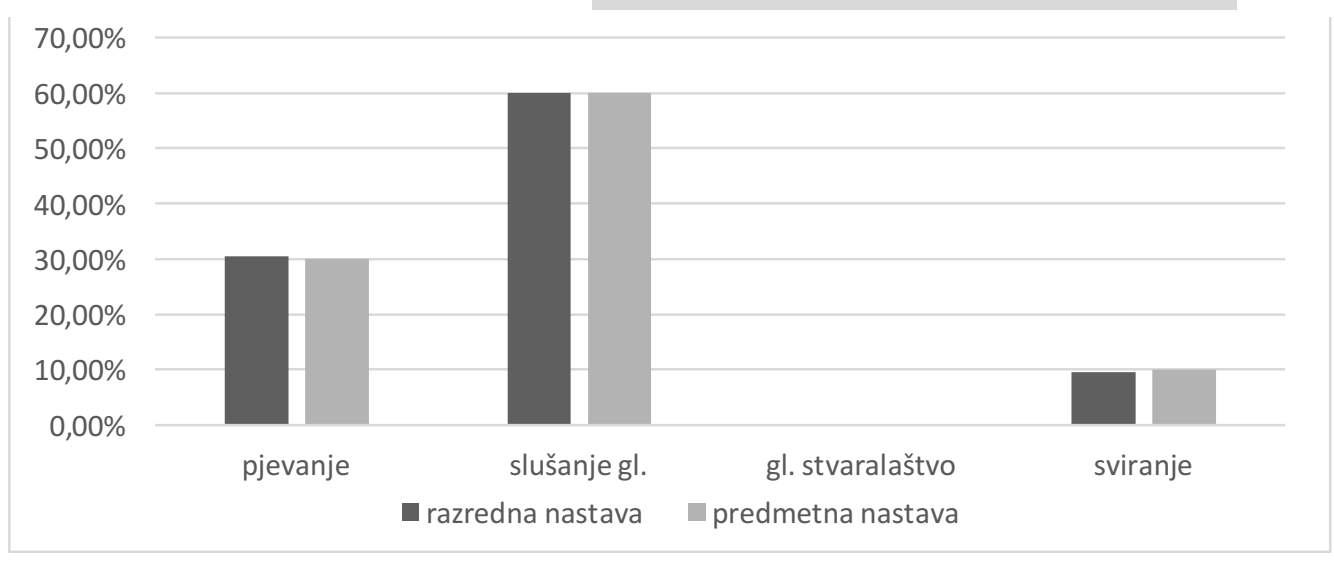

Slika 2. Najdraže aktivnosti nastave glazbe s obzirom na dob

\section{H8: Postoji utjecaj spola na preferiranje aktivnosti nastave glazbe.}

Na temelju rezultata provedenog hi-kvadrat testa s varijablama spola i glazbenim aktivnostima $\left(\chi^{2}=0,33 ; d f=2 ; p=0,85\right)$ nije potvrđen utjecaj spola na preferiranje aktivnosti nastave glazbe. Najdraža je aktivnost u objema skupinama slušanje glazbe, slijedi pjevanje i na posljednjem mjestu sviranje, dok niti jedan učenik nije odabrao glazbeno stvaralaštvo (slika 3). Slijedom toga, odbacuje se postavljena hipoteza.

Na temelju dobivenih rezultata evidentno je kako je svim sudionicima glazbeno stvaralaštvo najmanje omiljena aktivnost nastave glazbe. Ispitujući učenike koje im je područje nastave glazbe najdraže, majmrže, najlakše i najteže, Rojko (2012, str. 113-114) navodi kako je „na listi najdražih aktivnosti stvaralaštvo na posljednjem, šestom mjestu, dok je na listi najlakših na petom; od njega je, dakle lakše slušanje glazbe, pjevanje, sviranje $i$ učenje muzikološkoih podataka, a teže jedino pjevanje po notama. Iz tih rezultata ne kanimo zaključiti kako je stvaralaštvo jedna od potpuno nepoželjnih aktivnosti u nastavi glazbe, već samo to da ono, čini se, ipak nije tako poželjno kao što ga ponekad prikazuju (glazbeni) pedagozi“ (Rojko, 2012, str. 113114).

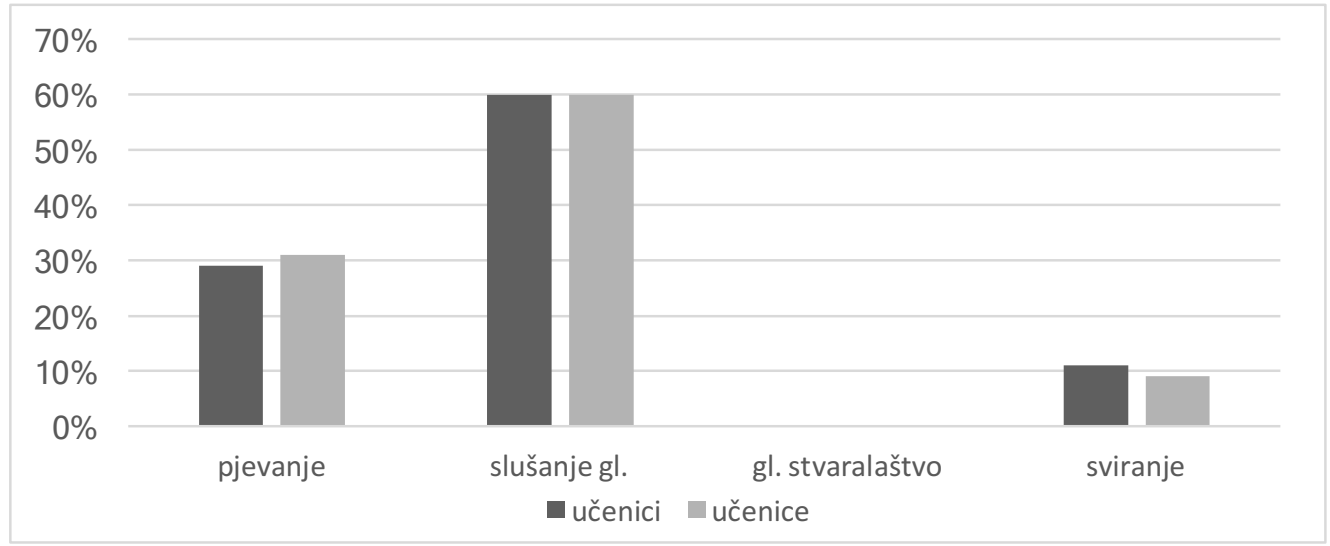

Slika 3. Najdraže aktivnosti nastave glazbe s obzirom na spol 
Što se tiče rangiranja predmeta Glazbena kultura u razrednoj nastavi, učenici najviše vole Tjelesnu i zdravstvenu kulturu, dok je predmet Glazbena kultura na drugom mjestu. Kod učenika predmetne nastave ponovno je Tjelesna i zdravstvena kultura na prvom mjestu, dok je Glazbena kultura na predzadnjem mjestu. Učenici trećeg razreda gimnazije najviše vole Psihologiju, dok Glazbenu umjetnost smještaju na peto mjesto od ukupno šesnaest predmeta. Učenici završnih razreda gimnazije najviše vole Biologiju, dok se Glazbena umjetnost nalazi na šestom mjestu od ukupno četrnaest predmeta.

Dobiveni rezultati slični su rezultatima Mirkov (2002) koja je istraživala stavove učenika osmog razreda prema nastavnim predmetima i uočila da su najbolje rangirani predmeti Biologija i Tjelesna i zdravstvena kultura, a za njima slijede strani jezik i Matematika. Uočene su i razlike u spolu s obzirom na stavove prema nastavnim predmetima, pa tako učenici imaju pozitivnije stavove prema Tehničkoj kulturi, Tjelesnoj i zdravstvenoj kulturi i Povijesti, a djevojčice prema materinskom i stranom jeziku te Biologiji.

\section{ZAKUUČAK}

Rezultatima ovoga istraživanja potvrđeno je kako gimnazijalci u odnosu na učenike osnovne škole provode više vremena dnevno slušajući glazbu. Nadalje, učenici čiji roditelji slušaju klasičnu glazbu imaju znatno pozitivnije stavove prema Glazbenoj kulturi / Glazbenoj umjetnosti u odnosu na učenike čiji roditelji ne slušaju takvu glazbu. Time je potvrđena važna uloga obiteljskog okruženja u oblikovanju glazbenog ukusa mladih. Nije potvrđena povezanost dodatne glazbene poduke sa stavovima prema nastavi glazbe, što je moguće objasniti malim brojem učenika koji takvu poduku pohađaju. Nadalje, učenici koji preferiraju klasičnu glazbu, imaju pozitivnije stavove prema Glazbenoj kulturi / Glazbenoj umjetnosti u odnosu na ostale učenike. Rezultatima istraživanja potvrđeno je i to da mlađi učenici imaju pozitivnije stavove prema nastavi glazbe u odnosu na starije učenike. Nije potvrđen utjecaj spola na stavove prema Glazbenoj kulturi / Glazbenoj umjetnosti. Slušanje je aktivnost nastave glazbe koju učenici najviše preferiraju, dok najmanje pozitivne stavove imaju prema glazbenom stvaralaštvu.

Što se tiče rangiranja predmeta Glazbena kultura u razrednoj nastavi, utvrđeno je da se predmet nalazi na drugom mjestu, dok je u predmetnoj nastavi na predzadnjem mjestu. Učenici trećeg razreda gimnazije Glazbenu umjetnost smještaju na peto, a učenici četvrtih razreda gimnazije na šesto mjesto.

Činjenica da mlađi učenici u odnosu na starije učenike imaju pozitivnije stavove prema nastavi glazbe važna je za glazbene pedagoge s različitih aspekata. Prije svega, zahvaljujući fleksibilnosti i otvorenosti učenika prema različitim glazbenim podražajima, učenike je od najranije dobi potrebno okružiti kvalitetnim i raznovrsnim glazbenim ostvarenjima. Međutim, ostaje otvorenim pitanje zašto s porastom dobi opada interes prema nastavi glazbe. Jedan od mogućih odgovora mogao bi se povezati s razvojnim osobinama učenika različite dobi. Dio odgovora na postavljeno pitanje vjerojatno leži u koncepciji same nastave jer, kako ističe Ross (1995), nepopularnost nastave glazbe u srednjoj školi rezultat je neuspjelih pokušaja moderniziranja glazbenog kurikuluma. Naime, učitelji se drže standardnih okvira i ne prilagođavaju se novim izazovima. Moguće je kako bi se promjenom koncepcije nastave glazbe promijenili i stavovi učenika prema njoj. 


\section{LITERATURA}

Arnett, J. J. (1995) Adolescents' uses of media for self-socialisation. Journal of Youth and Adolescence, 24, 519-533. doi: 10.1007/BF01537054

Barbarić, S. (2017) Stavovi učenika osnovne škole prema nastavi Glazbene culture. Diplomski rad. Split: Filozofski fakultet.

Bohner, G. (2003) Stavovi. U Hewstone, M. \& Stroebe, W. (Ur.), Uvod u socijalnu psihologiju, europske perspektive (str. 195-234). Jastrebarsko: Naklada Slap.

Brown, J. D., i Bobkowski, P.S. (2011) Older and newer media: Patterns of use and effects on adolescents' health and well-being. Journal of Research on Adolescence, 21, 95-113.

Crowther, R. D., i Durkin, K. (1982) Sex- and age-related differences in the musical behaviour, interests and attitudes towards music of 232 secondary school students. Educational Studies, 20, 13 18. doi: $10.1080 / 0305569820080206$

Dobrota, S. (2016) Stavovi studenata prema umjetničkoj glazbi i glazbenoj nastavi. Školski vjesnik. Časopis za pedagogijsku teoriju i praksu, 65, 33-47.

Dobrota, S. i Barbarić, S. (2017) Croatian elementary school students' attitudes towards music lessons. The Journal of Music Education of the Academy of Music in Ljubljana, 26, 5-19.

Dobrota, S., i Obradović, I. (2012) Stavovi učenika osnovne škole prema glazbi i nastavi glazbe. Školski vjesnik. Časopis za pedagoška i školska pitanja, 61 (1-2), 115-131.

Dobrota, S., i Reić Ercegovac, I. (2011) Stavovi učenika prema glazbi i nastavni glazbene kulture. Školski vjesnik. Časopis za pedagoška i školska pitanja, 60 (2), 199-210.

Eagly, A. \& Chaiken, S. (1993) The Psychology of Attitudes. Orlando, FL: Harcourt Brace Jovanovich, Inc.

Haladyna, T., i Thomas, G. (2015) The Attitudes of Elementary School Children toward School and Subject Matters. The Journal of Experimental Education, 48 (1), 18-23. doi: 10.1080/00220973.1979.11011707

Harland, J. (2000) Arts Education in Secondary School: Effects and Effectiveness. Slough: NFER.

Holfve-Sabel, M.-A. (2007) A comparison of student attitudes toward school, teachers and peers in Swedish comprehensive schools now and 35 years ago. Educational Research, 48 (1), 55-75. doi: $10.1080 / 00131880500498446$

Labak, I., Heffer, M., i Radanović, I. (2014) Stavovi učenika o nastavi prirode i biologije organiziranoj u dvosatu. Educatio Biologiae, 1, 36-48.

Larson, R. (1995) Secrets in the bedroom: Adolescents' private use of media. Journal of Youth and Adolescence, 24, 535-550. doi: 10.1007/BF01537055

McPherson, G. E. (2006) The child as musician: A handbook of musical development. Oxford: Oxford University Press.

Miranda, D. (2013) The role of music in adolescent development: much more than the same old song. International Journal of Adolescence and Youth, 18 (1), 5-22. doi.org/10.1080/02673843.2011.650182

Mirkov, S. I. (2002) Neki činioci formiranja stavova prema nastavnim predmetima. Nastava i vaspitanje, 51 (5), 383-399.

Nastavni plan i program za osnovnu školu (2006) Zagreb: Ministarstvo znanosti, obrazovanja i športa.

Nastavni program za gimnazije. Glazbena umjetnost. (1999) Zagreb: Glasnik Ministarstva prosvjete i sporta Republike Hrvatske.

North, A. C., i Hargreaves, D. J. (1999) Music and adolescent identity. Music Education Research, 1, 75-92. doi: 10.1080/1461380990010107

North, A. C., Hargreaves, D. J., i O'Neill, S. A. (2000) The importance of music to adolescents. British Journal of Educational Psychology, 70, 255-272. doi: 10.1348/000709900158083

Rentfrow, P. J., i Gosling, S. D. (2003) The do re mi's of everyday life: The structure and personality correlates of music preferences. Journal of personality and social psychology, 84, 1236-1256. doi: 10.1037/0022-3514.84.6.1236 
Rentfrow, P. J., i Gosling, S. D. (2006) Message in a ballad. The role of music preferences in interpersonal perception. Psychological Science, 17, 236-242. doi: 10.1111/j.1467-9280.2006.01691.x

Rojko, P. (2012) Metodika nastave glazbe. Teorijsko-tematski aspekti. Preuzeto 25.3.2018. s https://bib.irb.hr/datoteka/566005.ROJKO_Metodika_nastave_glazbe._Teorijsko_tematski_as pekti.pdf

Ross, M. (1995) What's wrong with school music? British Journal of Music Education, 12, 185-201. doi: 10.1017/S0265051700002692

Ross, M. (1998) Missing solemnis: Reforming music in schools. British Journal of Music Education, 15, 255-262. doi: 10.1017/S0265051700003934

Sunara, N. (2016) Glazbene preferencije i stavovi učenika prema umjetničkoj glazbi i glazbenoj nastavi. Diplomski rad. Split: Filozofski fakultet.

\section{Students' Attitudes Towards Music Culture and Musical Art}

Summary: Summary: The paper reviews the attitudes of elementary and high school students towards the teaching of Music Culture and Musical Arts in terms of their gender, age, family environment, additional music instruction, preference for classical music, and preferences of certain activities of music teaching. A general questionnaire and a questionnaire for examining the attitudes of students according to the subject of Music Culture/Musical Arts were used during the research. The survey was conducted on a sample of 245 students of the third, fourth, seventh, and eighth grades of elementary school and third and fourth grades of high school. The results of this research confirm that high school students spend more time daily listening to music than primary school students. Pupils who prefer classical music and students whose parents listen to classical music have more positive attitudes towards subjects of Music Culture/Musical Art. The results of the research confirm that younger students have more positive attitudes towards music teaching than older students. Students have the most positive attitudes towards listening, and the least positive attitudes toward musical creation. No correlation between additional music instruction and sex influence on attitudes towards music teaching were confirmed.

Keywords: music preferences, music classes, elementary school, high school, attitudesteaching were confirmed.

\section{Einstellungen von Schülern zum Musikunterricht}

Zusammenfassung: Die Arbeit untersuchte die Einstellungen von Grundschülern und Gymnasiasten zum Musikunterricht in Bezug auf ihr Geschlecht, Alter, Familienhintergrund, zusätzlichen Musikunterricht, Vorliebe für klassische Musik und Vorliebe für bestimmte Aktivitäten im Musikunterricht. Für die Erhebung wurde ein Fragebogen zu allgemeinen Daten, sowie ein Fragebogen zur Erhebung der Einstellungen von Schülern zum Fach Musik verwendet. Die Untersuchung wurde auf einer Stichprobe von 245 Schülern der dritten, vierten, siebten und achten Klasse der Grundschule, sowie dritten und vierten Klasse des Gymnasiums (bzw. 11. u. 12. Klasse Oberstufe) durchgeführt. Die Ergebnisse dieser Untersuchung bestätigen, dass Gymnasiasten im Vergleich zu Grundschülern täglich mehr Zeit beim Musikhören verbringen. Schüler mit Vorliebe für klassische Musik und Schüler, deren Eltern klassische Musik hören, haben positivere Einstellungen zum Musikunterricht. Die Ergebnisse haben außerdem bestätigt, dass jüngere Schüler positivere Einstellungen zum Musikunterricht haben als ältere. Hören ist die beliebteste Aktivität im Musikunterricht, während die am wenigsten positiven Einstellungen zur Aktivität der musikalischen Produktion vorherrschen. Ein Zusammenhang zwischen zusätzlichem Musikunterricht und Geschlecht auf die Einstellungen zum Musikunterricht konnte nicht festgestellt werden.

Schlüsselwörter: Musikvorliebe, Musikunterricht, Grundschule, Sekundarschule, Einstellungen 